\title{
BRAF inhibitors: from the laboratory to clinical trials
}

${ }^{1}$ MA Rahman, ${ }^{1}$ A Salajegheh, ${ }^{1}$ RA Smith, ${ }^{1}$ A K-Y Lam

${ }^{1}$ Cancer Molecular Pathology Group, Griffith Health Institute, Griffith University, Gold Coast, Australia

Correspondence to: Professor Alfred Lam, Head of Pathology, Griffith Medical School, Gold Coast Campus, Gold Coast QLD 4222, Australia. a.lam@griffith.edu.au

Telephone +61 $756780718 \quad$ Fax +61 756780708

Keywords: BRAF, BRAF, kinase inhibitors, multi-kinase inhibitor, clinical trial

Corresponding Author Biography: Prof. Alfred Lam is Chair Professor of Pathology at Griffith Medical School. He has worked in Hong Kong, the USA and Australia, primarily in endocrine and general cancer pathology. He is an internationally recognized authority in diagnostic and molecular pathology of cancer with more than 20 years of activity in this field. He has contributed to World Health Organization and Royal College of Pathologists of Australasia books for the classification and reporting of endocrine tumours.

\section{Table of Contents:}

1 Introduction

2 BRAF kinase inhibitors

3 Type-I BRAF Inhibitors

3.1 Vemurafenib (PLX4032/RG7204/RO5185426) 
3.1.1 Preclinical study

3.1.2 Clinical trials

\subsubsection{Toxicities}

3.1.3.1 General symptoms

3.1.3.2 Skin toxicities

3.2 Dabrafenib (GSK2118436)

3.2.1 Preclinical study

3.2.2 Clinical trials

3.2.3 Toxicities

3.2.3.1 General symptoms

3.2.3.2 Skin toxicities

3.3 LGX818

3.3.1 Preclinical study

3.3.2 Clinical trials

3.4 PLX4720

3.4.1 Preclinical study

3.5 SB-590885

3.5.1 Preclinical study

3.6 GDC-0879

3.6.1 Preclinical study

4 Type-II BRAF Inhibitors

4.1 Sorafenib (BAY 43-9006)

4.1.1 Preclinical study

4.1.2 Clinical trials

4.1.3 Toxicities 
4.1.3.1 General symptoms

4.1.3.2 Skin toxicities

4.2 Regorafenib (BAY 73-4506)

4.2.1 Preclinical study

4.2.2 Clinical trials

4.2.3 Toxicities

4.2.3.1 General symptoms

4.2.3.2 Skin toxicities

4.3 XL281 (BMS-908662)

4.3.1 Preclinical study

4.3.2 Clinical trials

4.3.3 Toxicities

4.4 RAF265

4.4.1 Preclinical study

4.4.2 Clinical trials

4.4.3 Toxicities

5 Unclassified BRAF inhibitor

5.1 ARQ736

5.1.1 Preclinical study

5.1.2 Clinical trials

6 Conclusion 
Abstract: $B R A F$ is one of the most commonly mutated proto-oncogenes and plays a significant role in the development of numerous cancers of high clinical impact. Due to the commonality of BRAF mutations, a number of BRAF inhibitors have been developed as tools in the management of patients with cancers dependent on the action of mutant BRAF to drive cellular proliferation. In this review, we examine the current state of clinical trials and laboratory research concerning BRAF inhibitors in development and available for clinical use. We contrast the effectiveness of type-I and type-II BRAF inhibitors, the former typically showing much more restricted inhibitory selectivity and greater patient response rates. 


\section{Introduction}

$B R A F$ (v-raf murine sarcoma viral homolog B1) is a proto-oncogene which is a member of rapidly accelerated fibrosarcoma (RAF) kinase family proteins. RAF proteins are serine/threonine kinases which were originally identified as retroviral oncogenes in 1983 [14]. So far, three RAF kinase proteins have been identified which are: ARAF, BRAF and CRAF. CRAF was first discovered in 1985, ARAF in 1986 and BRAF in 1988. CRAF is also known as Raf-1 [5-8]. ARAF (the smallest isoform) is $68 \mathrm{kDa}$, CRAF ranges from 72$74 \mathrm{kDa}$ and BRAF ranges from 75 to $100 \mathrm{kDa}$ [9-11]. BRAF is the most potent activator of MEK kinases (a downstream effector of RAF) when compared with ARAF and CRAF [1, 2, $4,12]$.

The BRAF kinase domain adopts a bilobal structure (named as small lobe and large lobe) which is separated by a catalytic cleft (Fig. 1). An aspartic acid residue in the N-region of the BRAF protein stabilizes its small lobe [4, 12-14]. However, the conserved aspartate, phenylalanine and glycine (DFG) motif of BRAF shows flipped orientation when it is in inactive conformation (DFG-out). As a consequence, the glycine rich loop and activation segment of the BRAF kinase domain come close to each other, which results hydrophobic interaction between these two regions. Because of the hydrophobic interaction, the catalytic cleft of BRAF becomes inaccessible for ATP (adenosine triphosphate) [15]. Disruption of the hydrophobic interaction between the glycine rich loop and activation segment (due to phosphorylation in the activation segment) results the DFG motif flipping to its active orientation (DFG-in). As a consequence, the catalytic cleft becomes accessible again for ATP $[12,15]$.

Most BRAF mutations happen in the glycine rich loop and activation segment $[4,12$, $14,15]$. The main result is to destabilize the hydrophobic interaction between the glycine rich loop and activation segment, changing the protein permanently to its active conformation 
and increasing kinase activity of BRAF [14]. More than 65 BRAF mutations have been discovered at the time of writing $[8,12,16]$. Of these, the V600E mutation is the most frequent (comprising more than 90\%) among all BRAF mutations. This mutation happens near the DFG motif in the activation segment of BRAF where valine (V) is substituted with glutamic acid (E) [12, 15]. This BRAF mutation destabilizes the hydrophobic interaction between the glycine rich loop and activation segment. As a result, the DFG motif of BRAF flips to its active orientation (DFG-in), achieving a 500 fold increase in kinase activity [12, 15]. In addition, because of this mutation, BRAF becomes self-sufficient in sending signalling for cellular proliferation and survival without receiving any upstream or external stimuli, which results in uncontrolled cellular proliferation and survival activities $[12,14,15]$. $B R A F$ mutation is found to be around $8 \%$ of all cancers and most frequently occurs in melanoma (40-80\%), thyroid cancer (36-53\%), colorectal cancers (5-22\%), ovarian serous cancer ( 30\%) and few other cancers like gliomas, hary cell leukaemia, non-small cell lung carcinoma, hepatobiliary carcinoma $[4,16-18]$. In addition, $B R A F$ is found be associated with poor outcomes in a few cancers. In metastatic melanoma with BRAF mutation, the median survival was found to be only 5.7 months without any BRAF inhibitor treatment [19]. In thyroid, the most common type of malignancy is papillary thyroid carcinoma where BRAF V600E mutation is considered as poor prognostic marker [20, 21]. Moreover, BRAF V600E mutation is also associated with poor outcome in patients with colorectal cancer which is found in independent studies [22, 23].

\section{BRAF kinase inhibitors}

Kinases play a very important role in all kinds of cellular physiology. 518 kinases are found to be encoded in human genome. Dysfunctions as well as deregulations of kinase activities are found to be responsible for causing a number of diseases in humans, including 
cancers $[24,25]$. Therefore, kinases are very important targets for drug development. In fact, more than a quarter of all pharmaceutical drugs are designed to target protein kinases. At present, protein kinases are the second most important group of drug targets after G-protein coupled receptors [26, 27].

All the BRAF kinase inhibitors so far developed are small molecules and are divided into two types: Type-I and Type-II inhibitors [28]. Type-I BRAF inhibitor binds with the protein kinase in its active (DFG-in) conformation (Fig. 2). They interact with the hinge region of BRAF by forming 1-3 hydrogen bonds with the kinase hinge residues. They also interact with the ATP binding site of the protein kinase by forming hydrophobic bonds in and around of adenine regions where the adenine ring of ATP usually binds [27-30]. On the other hand, type-II BRAF inhibitor binds with the protein kinase in its inactive (DFG-out) conformation (Fig. 3). They form hydrogen bonds with the residues in $\alpha$ C-helix and DFG motif in the allosteric site $[27,28,30]$. Type-II BRAF inhibitors create links with allosteric sites via van der Waals interactions (a non-polar force occurring between any two molecules, regardless of their charge). The allosteric site is made by DFG-out conformation of BRAF and is adjacent to the ATP binding pocket. Type-II inhibitors can also form hydrogen bonds

with the kinase hinge residues by extending them into the adenine region of ATP binding pocket [27, 28, 30-33]. A summarization of BRAF inhibitors is shown in Table 1.

\section{Type-I BRAF Inhibitors}

\subsection{Vemurafenib (PLX4032/RG7204/RO5185426)}

\subsubsection{Preclinical study}

Vemurafenib is found to be a potent inhibitor of BRAF V600E and other BRAF (V600D, V600K, and V600R) mutants, but not wild-type BRAF in melanoma cell lines 
although it was found to inhibit wild-type BRAF in other cell lines at higher concentration. It also showed potent activity in xenograft models of BRAF V600E mutated melanoma [28, 34]. In addition, robust inhibitory activity of vemurafenib was also found against BRAF mutated melanoma cell lines in another study [35]. Vemurafenib inhibits V600E mutant BRAF $\left(\mathrm{IC}_{50}=31 \mathrm{nM}\right)$, CRAF (IC $\left.50=48 \mathrm{nM}\right)$, wild-type BRAF $\left(\mathrm{IC}_{50}=100 \mathrm{nM}\right)$ as well as over 200 other kinases at higher concentration [36].

\subsubsection{Clinical trials}

The Phase-I clinical (BRIM1) trial of vemurafenib was divided into two phases: a dose escalation phase and an extension phase. In the dose escalation phase, a total of 55 patients (including 49 melanoma patients) participated, whereas 32 metastatic melanoma patients were enrolled in the extension phase study [36-39]. $960 \mathrm{mg} / \mathrm{kg}$ twice daily was found to be the tolerable dose of Vemurafenib for humans in the dose escalation phase, where partial or complete regression of melanoma bearing BRAF V600E mutation was observed in most of the patients. In the extension phase, the response rate was $81 \%$ (26 patients out of 32 patients) where 2 patients showed complete response and 24 patients showed partial response to the therapy. The median progression free survival was more than 7 months in that trial.

In the Phase-II clinical (BRIM2) trial of vemurafenib, a total of 132 BRAF V600E mutated melanoma patients who received treatment previously participated [39-42]. In this trial, the response rate was 53\% (70 patients out of 132 patients) where 8 (6\%) patients showed complete response and 62 (47\%) patients showed partial response to the therapy. In addition, 38 (29\%) patients had stable disease. The median survival and median progression free survival were 15.9 and 6.7 months respectively in that trial.

The Phase-III clinical (BRIM3) trial of vemurafenib was performed on 675 BRAF V600E mutated metastatic melanoma patients who did not receive any previous treatment. In 
that trial (until October 3, 2011), the median overall survival was 13.2 months in vemurafenib group, compared to 9.9 months in the dacarbazine group (a positive control group) [43, 44]. In addition (until December 30, 2010), 48.4\% patients showed significant response (2 patients showed complete response and 104 patients showed partial response) in the vemurafenib group, whereas only 5.5\% response was seen in the dacarbazine group. The median progression free survival (until February 1, 2012) was 6.9 months in the vemurafenib group, whereas it was only 1.6 months in the dacarbazine group [42-44]. The drug was approved for the treatment of metastatic melanoma bearing BRAF V600E mutation by the U.S. Food and Drug Administration (FDA) in 2011 [28, 39].

\subsubsection{Toxicities}

\subsubsection{General symptoms}

General adverse symptoms associated with vemurafenib treatment were alopecia, nausea, fatigue, lymphopenia, neutropenia, headache and diarrhoea [37, 40, 42, 43, 45, 46].

\subsubsection{Skin toxicities}

Common skin toxicities associated with vemurafenib treatment were squamous cell carcinoma, basal cell carcinoma, keratoacanthoma, rash, photosensitivity, actinic keratosis, verrucal keratosis, Grover’s disease, plantar hyperkeratosis, warts, milia, pruritus, skin papilloma, arthralgia [37, 40, 42, 43, 45, 46].

\subsection{Dabrafenib (GSK2118436)}

\subsubsection{Preclinical study}

Dabrafenib is able to inhibit V600E mutated BRAF very efficiently where half maximal inhibitory concentration $\left(\mathrm{IC}_{50}\right)$ is $0.8 \mathrm{nM}[47,48]$. It also inhibits wild-type BRAF 
$\left(\mathrm{IC}_{50}=3.2 \mathrm{nM}\right), \mathrm{CRAF}\left(\mathrm{IC}_{50}=5 \mathrm{nM}\right)$ and few other kinases at higher concentration.

Dabrafenib has shown efficacy in growth inhibition both in BRAF V600E mutated cell lines as well as xenograft models of melanoma and colorectal cancers $[47,48]$. In addition, it is also effective to inhibit proliferative activities in other BRAF (V600D and V600R) mutated melanoma cell lines [49].

\subsubsection{Clinical trials}

In the dose escalation phase of Phase-I clinical trial of dabrafenib (BREAK-2), a total of 184 patients participated where 156 patients had with metastatic melanoma and the remaining patients had non-metastatic disease [50]. In this trial, BRAF V600E mutated as well as other BRAFV600 mutated (like V600K, V600D) metastatic melanoma patients were included. Some patients were also previously treated with other drugs. The maximum tolerable dose for dabrafenib determined in the study was $150 \mathrm{mg}$ twice daily. 25 patients (69\%) out of 36 BRAF V600 mutated melanoma patients showed partial or complete response and 18 patients (50\%) showed confirmed response in that study. In addition, 21 patients (78\%) out of 27 BRAF V600E mutated melanoma patients showed partial or complete response and 15 patients (56\%) showed confirmed response. Among the 36 melanoma patients without cerebral metastases, the median duration of response was 6.2 months. The median progression free survival for BRAF V600E and BRAF V600K mutated melanoma patients were 5.5 and 5.6 months respectively in that trial. In the previously untreated 26 brain metastatic melanoma patients, the progression free survival was 4.2 months [39, 50, 51].

In the Phase-II clinical trial of Dabrafenib (BREAK-2), a total of 92 melanoma patients participated where 76 patients had BRAF V600E mutation and 16 patients had BRAF V600K mutation [51, 52]. The patients were treated with a dose of $150 \mathrm{mg}$ 
Dabrafenib twice daily. In that study, 7\% showed complete response and 53\% showed partial response in the BRAF V600E mutated patients. In addition, 13\% patients with BRAF V600K mutation showed partial response. The median progression free survivals were 6.75 months in the BRAF V600E mutated patients and 5 months in the BRAF V600K mutated patients in that trial. A further Phase-II clinical trial of dabrafenib (BREAK-MB) was conducted on patients with BRAF V600E/V600K mutated melanoma (metastatic to the brain) where a total of 172 patients were participated [53]. Of these patients, 39.2\% of treatment naïve patients with V600E mutations showed intra-cranial response while $30.8 \%$ of previously treated patients showed intra-cranial results. In case of V600K mutated patients that responses were $6.7 \%$ and $22.2 \%$ respectively in that trial.

In the Phase-III clinical trial of dabrafenib, a total of 250 patients (until December 19, 2011) with BRAF V600E mutated metastatic melanoma were enrolled where 187 patients received 150 mg dabrafenib twice daily and 63 patients received dacarbazine treatment (a positive control group) [54]. In that trial, 6 patients (3\%) in the dabrafenib group and one patient (2\%) in dacarbazine group showed complete response, whereas 87 patients (47\%) in dabrafenib group and 3 patients (5\%) in dacarbazine group showed partial response. In addition, 78 patients (42\%) in dabrafenib group and 30 patients (48\%) in dacarbazine group had a stable disease. The median progression free survival was 5.1 months in dabrafenib group and 2.7 months in dacarbazine group in that trial. Later, the U. S. Food and Drug Administration (FDA) approved dabrafenib for the treatment of patients with BRAF V600E mutated unresectable or metastatic melanoma on May 29, 2013 [55].

\subsubsection{Toxicities}

\subsubsection{General symptoms}


Common side effects associated with dabrafenib treatment were pyrexia, fatigue, headache, neutropenia, thrombocytopenia, leukopenia, asthenia, hyponatraemia, arthralgia, nausea, chills, myalgia, vomiting, diarrhoea and hair loss [28, 45, 46, 50-54, 56].

\subsubsection{Skin toxicities}

Skin toxicities associated with dabrafenib treatment were cutaneous squamous-cell carcinoma, basal cell carcinoma, rash, skin papillomas, keratoacanthoma, plantar hyperkeratosis, actinic keratosis, verrucal keratosis, seborrhoeic keratosis, verruca vulgaris, Grover's disease [28, 45, 46, 50-54, 56].

\subsection{LGX818}

\subsubsection{Preclinical study}

LGX818 is a highly potent and selective inhibitor of V600E mutated BRAF. It only inhibits the proliferative activities of cell lines that express V600E mutated BRAF, but does not inhibit proliferative activities of cell lines that express wild-type BRAF, which has been tested on more than 400 cell lines expressing wild-type BRAF [57]. In an experiment, LGX818 inhibited the proliferative activity of BRAF V600E mutated melanoma cell line (A375) with an $\mathrm{EC}_{50}$ of $4 \mathrm{nM}$. It was shown to induce tumor regression in multiple $B R A F$ mutated xenograft models on mice as well as rats at doses as low as $1 \mathrm{mg} / \mathrm{kg}$, but it did not induce tumor regression in wildtype $B R A F$ tumor xenograft models even at doses up to 300 $\mathrm{mg} / \mathrm{kg}$ twice daily [57]. It is also effective on metastatic melanoma as well as melanoma with brain metastasis. LGX818 has not shown any significant activities against other kinases even in higher concentrations ( $\left.\mathrm{IC}_{50}>900 \mathrm{nM}\right)$, tested against a panel of 100 different kinases [57]. 


\subsubsection{Clinical trials}

LGX818 is currently in Phase-I clinical trials on patients with advanced or metastatic BRAF mutated melanoma, currently registered (ID: NCT01436656) with ClinicalTrials.gov.

\subsection{PLX4720}

\subsubsection{Preclinical study}

PLX4720 is highly selective for BRAF and at lower concentrations, it only inhibits V600E mutated BRAF, not the wild-type BRAF. The half maximal inhibitory concentration $\left(\mathrm{IC}_{50}\right)$ of PLX4720 for V600E mutated BRAF protein is $13 \mathrm{nM}$. PLX4720 is also able to inhibit CRAF $\left(\mathrm{IC}_{50}=6.7 \mathrm{nM}\right)$, wide-type BRAF $\left(\mathrm{IC}_{50}=160 \mathrm{nM}\right)$ and other kinases at higher concentration [58]. It inhibits ERK phosphorylation only in cell lines that express V600E mutated BRAF, but not in the cell lines that express wild-type BRAF. The drug also potentially induces cell cycle arrest and apoptosis in BRAF V600E mutated cell lines, but not in BRAF wild-type cell lines. Moreover, treated animals showed delays in tumour growth as well as tumour regression in a xenograft model of BRAF V600E mutated tumour without showing any adverse effects $[28,58]$. PLX4720 was also found to inhibit proliferation, migration and invasion of BRAF V600E mutated anaplastic thyroid cancer (ATC) cell lines as well as in an orthotopic mouse model of anaplastic thyroid cancer (ATC) harbouring BRAF V600E mutation through downregulation of genes (like CCDN1, TSP-1 and ITGA6) involved in proliferation, migration and invasion [59].

\subsection{SB-590885}

\subsubsection{Preclinical study}

SB-590885 is a potent and extremely selective BRAF inhibitor which is able to inhibit ERK phosphorylation as well as proliferation of tumour cells that express V600E mutated 
BRAF [60]. It is highly selective to BRAF and CRAF which were tested against a panel of 48 different kinases. It inhibits BRAF through stabilizing the kinase domain of BRAF to the active conformation. It showed selectivity against BRAF with an inhibitory constant $\left(K_{i \text { app }}\right)$ of $0.16 \mathrm{nM}[28,60]$. In an experiment, SD-590885 inhibited V600E mutated BRAF in cell lines where half maximal effective concentration $\left(\mathrm{EC}_{50}\right)$ was $0.028-0.28 \mu \mathrm{M}$ as well as wildtype BRAF where $\mathrm{EC}_{50}$ was 1.1-6.1 $\mu \mathrm{M}$. At higher concentration, it also inhibited the growth of K-Ras or N-Ras mutated cell lines $\left(\mathrm{EC}_{50}=1.1\right.$ to1.5 $\left.\mu \mathrm{M}\right)$. The drug was also able to inhibit CRAF where its $K_{i}$ app is $1.72 \mathrm{nM}$. In addition, SB-590885 is able to decrease cellular transformation and tumorigenic properties of malignant cells expressing mutant BRAF [28, $60,61]$.

\subsection{GDC-0879}

\subsubsection{Preclinical study}

GDC-0879 is a highly selective and potent inhibitor of BRAF. It showed its inhibitory effects against BRAF in various in-vitro and cell based assay with half maximal inhibitory concentration $\left(\mathrm{IC}_{50}\right) 0.13 \mathrm{nM}$. It also showed its efficacy against CRAF when it was tested against a panel of 140 different kinases at a concentration of $1.0 \mu \mathrm{M}[62,63]$. GDC-0879 was also found to be effective against V600E mutated BRAF which was tested in both BRAF V600E mutated melanoma, colon and other cell lines as well as xenograft models. It also showed significant and dose dependent tumor growth inhibition in xenograft models of A375 (BRAF ${ }^{\mathrm{V} 600 \mathrm{E}}$ melanoma) and Colo205 (BRAF ${ }^{\mathrm{V} 600 \mathrm{E}}$ colorectal cancer) cell lines where median effective doses $\left(\mathrm{ED}_{50}\right)$ were 28 and $32 \mathrm{mg} / \mathrm{kg}$ respectively [62].

\section{Type-II BRAF Inhibitors}

\subsection{Sorafenib (BAY 43-9006)}




\subsubsection{Preclinical study}

Sorafenib is a multi-kinase inhibitor, although it was initially designed as a CRAF inhibitor. It is able to inhibit RAF kinsaes as well as receptor tyrosine kinases (RTKs) which are responsible for carcinogenesis $[15,64,65]$. It is able to inhibit CRAF $\left(\mathrm{IC}_{50}=6 \mathrm{nM}\right)$, wild-type BRAF ( $\left.\mathrm{IC}_{50}=25 \mathrm{nM}\right)$, VEGFR1 $\left(\mathrm{IC}_{50}=26 \mathrm{nM}\right)$, Flt-3 $\left(\mathrm{IC}_{50}=33 \mathrm{nM}\right)$, V600E mutated BRAF $\left(\mathrm{IC}_{50}=38 \mathrm{nM}\right), \mathrm{p} 38\left(\mathrm{IC}_{50}=38 \mathrm{nM}\right), \mathrm{RET}\left(\mathrm{IC}_{50}=47 \mathrm{nM}\right), \mathrm{c}-\mathrm{KIT}\left(\mathrm{IC}_{50}=68\right.$ nM), VEGFR2 ( $\left.\mathrm{IC}_{50}=90 \mathrm{nM}\right)$, FGFR1 $\left(\mathrm{IC}_{50}=580 \mathrm{nM}\right)$ and other kinases [65-69].

\subsubsection{Clinical trials}

In the Phase-I clinical trials of Sorafenib, the maximum tolerable dose (MTD) was found to be $400 \mathrm{mg}$ twice daily. In four different Phase-I clinical trials of the drug, a total of 173 patients participated where 2 patients (one with renal cell carcinoma and one with hepatocellular carcinoma) out of 137 evaluable patients showed partial response and 38 patients (28\%) had stable disease [65, 70-73]. In addition, a few other Phase-I clinical trials of Sorafenib were also conducted and still are being conducted on different cancers.

A number of Phase-II clinical trials of Sorafenib have been conducted and are still underway on different cancers like melanoma, thyroid cancers, renal cell cancer, biliary tract cancer, breast cancer, prostate cancer, hepatocellular cancer, non-small cell lung cancer and others [74-83]. One of the Phase-II clinical trials was performed in advanced melanoma where a total of 37 patients were treated with Sorafenib with a dose of $400 \mathrm{mg}$ twice daily [74]. In the trial, 19\% patients had stable disease (SD), 62\% patients had progressive disease (PD) and 19\% patients were unevaluable. The overall median progression free survival was 2.75 months in that trial.

Additionally, a number of Phase-III clinical trials of Sorafenib were conducted and some are still being conducted on different cancers like hepatocellular carcinoma, renal cell 
carcinoma, thyroid carcinoma and others [84-88]. One of the Phase-III clinical trials of sorafenib (SHARP trial) was done on advanced hepatocellular carcinoma patients where a total of 602 patients were randomised to treat with either 400 mg sorafenib twice daily (299 patients) or placebo (303 patients) $[84,89]$. In that trial, 7 patients $(2 \%)$ showed partial response and 211 patients (71\%) had a stable disease in sorafenib group whereas 2 patients (1\%) showed partial response and 204 patients (67\%) had a stable disease in placebo group. Median time to symptomatic progression was 4.1 months in sorafenib group and 4.9 months in placebo group. In addition, median time to radiological progression was 5.5 months in sorafenib group and 2.8 months in placebo group. Also, the median overall survival was 10.7 months in sorafenib group and 7.9 months in placebo group in that trial.

Another Phase-III clinical (DECISION) trial of sorafenib was completed on locally advanced / metastatic patients with radioactive iodine (RAI) refractory differentiated thyroid cancer which was registered (ID: NCT00984282) with ClinicalTrials.gov. In the trial, a total of 417 patients were included where 207 patients were treated with 400 mg sorafenib twice daily and 210 patients were treated with placebo [90]. The median overall survival was found 10.8 months in sorafenib group as compared to 5.8 months in placebo group. Sorafenib showed only partial response in the trial which was $12.2 \%$ whereas it was $0.5 \%$ in placebo group. The full clinical trial report was not available during this manuscript preparation.

Sorafenib showed some efficacy in the treatment of patients with hepatocellular carcinoma (HCC) and renal cell carcinoma (RCC). The efficacy of sorafenib in this case is hypothesised to be the inhibition of other kinases like VEGFR2, KIT and Flt-3, rather than BRAF kinase. Finally, Sorafenib was approved for the treatment of advanced renal cell carcinoma and unresectable hepatocellular carcinoma patients by U.S. Food and Drug Administration (FDA) [66, 74, 91-95]. 


\subsubsection{Toxicities}

\subsubsection{General symptoms}

The common toxicities associated with Sorafenib treatment fatigue, anorexia, voice change, diarrhoea, headache, joint pain, pruritus, weight loss, hypertension, nausea, vomiting, alopecia, flushing, constipation, haemorrhage (upper GI), neuropathy, stomatitis, hypophosphatemia, musculoskeletal pain and abdominal pain [46, 65, 74, 75, 84, 85, 88-90, 96].

\subsubsection{Skin toxicities}

Skin toxicities associated with Sorafenib treatment were squamous cell carcinoma, actinic keratosis, rash/desquamation, dry skin and hand-foot skin reaction $[46,65,74,75,84$, 85, 88-90, 96].

\subsection{Regorafenib (BAY 73-4506)}

\subsubsection{Preclinical study}

Regorafenib is a multi-kinase inhibitor. It is able to inhibit both wild-type BRAF $\left(\mathrm{IC}_{50}=28 \mathrm{nM}\right)$ as well as V600E mutated BRAF $\left(\mathrm{IC}_{50}=19 \mathrm{nM}\right)$. It is also able to inhibit CRAF $\left(\mathrm{IC}_{50}=2.5 \mathrm{nM}\right), \operatorname{RET}\left(\mathrm{IC}_{50}=1.5 \mathrm{nM}\right), \operatorname{VEGFR2}\left(\mathrm{IC}_{50}=4.2 \mathrm{nM}\right), \mathrm{c}-\mathrm{KIT}\left(\mathrm{IC}_{50}=7 \mathrm{nM}\right)$, VEGFR1 $\left(\mathrm{IC}_{50}=13 \mathrm{nM}\right)$, PDGFR- $\beta\left(\mathrm{IC}_{50}=22 \mathrm{nM}\right)$, VEGFR3 $\left(\mathrm{IC}_{50}=46 \mathrm{nM}\right), \mathrm{FGRF} 1\left(\mathrm{IC}_{50}\right.$ $=202 \mathrm{nM})$, TIE2 $\left(\mathrm{IC}_{50}=311 \mathrm{nM}\right)$ and other kinases [28, 97].

\subsubsection{Clinical trials}

A number of Phase-I clinical trials of regorafenib were conducted and are still being conducted on colorectal cancer, solid tumors, renal cancer and others. The maximal tolerable 
dose was determined $160 \mathrm{mg}$ once daily in a 21 days on and 7 days off schedule in that trial [98-100]. One of the Phase-I clinical trials of regorafenib was done in patients with metastatic colorectal cancer, where a total of 38 patients participated [98]. In that study, 27 patients were evaluable for response where 1 patient (4\%) showed partial response and 19 patients (70\%) had a stable disease. The median progression free survival observed in that study was 3.8 months.

A number of Phase-II clinical trials of regorafenib are also either completed or ongoing on GI stromal tumor, renal cell carcinoma, hepatocellular carcinoma, soft tissue sarcoma and others [101-103]. In a Phase-II trial conducted on intermediate or advanced hepatocellular carcinoma, a total of 36 patients were treated with 160 mg regorafenib once daily [103]. In that trial, one patient (3\%) showed partial response and 25 patients (69\%) had a stable disease. The median time to progression was 4.3 months and the median overall survival was 13.8 months in that study.

Similarly, Phase-III clinical trials of regorafenib have also been conducted and more are being undertaken on colorectal cancer, GI stromal tumors, hepatocellular carcinoma and others [104, 105]. A Phase-III clinical trial in metastatic colorectal cancer had a total of 760 patients, randomised to treat with either $160 \mathrm{mg}$ regorafenib daily (505 patients) or placebo (255 patients) [104]. In that trial (until July 21, 2011), 5 patients (1\%) showed partial response in regorafenib group whereas one patient $(0.4 \%)$ showed partial response in placebo group. The median overall survival was 6.4 months in regorafenib group and 5 months in placebo group. In addition, the median progression free survival (PFS) was 1.9 months in regorafenib group and 1.7 months in placebo group in that study. The US Food and Drug Administration (FDA) has approved regorafenib for the treatment of patients with metastatic colorectal cancer and unresectable metastatic GI stromal tumors [106, 107]. 


\subsubsection{Toxicities}

\subsubsection{General symptoms}

The most common toxicities associated with regorafenib treatment were hypertension, muscular pain, weight loss, thrombocytopenia, hyperuricemia, diarrhoea, voice change, taste alteration, sensory neuropathy, nose bleed, dyspnoea, oral mucositis, alopecia, anorexia, myalgia, hoarseness, nausea, constipation, vomiting, renal failure, hyponatraemia, hypophosphataemia, hypothyroidism, hyperthyroidism, headache, proteinuria, anaemia, abdominal pain, fever, dehydration, hyper-bilirubinaemia and fatigue [98, 99, 101-105, 108, 109].

\subsubsection{Skin toxicities}

Skin toxicities associated with regorafenib treatment were hand-foot skin reaction, rash/desquamation and dry skin [98, 99, 101-105, 108, 109].

\subsection{XL281 (BMS-908662)}

\subsubsection{Preclinical study}

XL281 is a potent and selective RAF inhibitor. It is able to inhibit wild-type BRAF $\left(\mathrm{IC}_{50}=5 \mathrm{nM}\right)$, V600E mutated BRAF $\left(\mathrm{IC}_{50}=6 \mathrm{nM}\right)$ as well as CRAF $\left(\mathrm{IC}_{50}=3 \mathrm{nM}\right)$, these concentration ranges being highly similar $[28,110]$.

\subsubsection{Clinical trials}

In the Phase-I clinical trial of XL281, a total of 30 patients including melanoma, papillary thyroid carcinoma (PTC), colorectal carcinoma (CRC), non-small cell lung carcinoma (NSCLC) and other solid tumor patients participated [28, 111]. Its oral maximum tolerated dose (MTD) was determined to be150 mg in the dose escalation phase of the trial. 
One patient with ocular melanoma showed partial response and 12 patients had a stable disease (including 2 patients with PTC harbouring BRAF V600E mutation) in that study. In

addition, 9 patients showed 5-29\% decrease in target lesions. 4 patients (including 3 melanoma patients) showed 72\% decrease in phosphorylated-MEK and 68\% decrease in phosphorylated-ERK in their biopsy samples which were taken after treatment with XL281. Moreover, 13 patients (43\%) demonstrated clinical benefit (partial response or stable disease) in that study.

A Phase-I/II clinical trial of XL281 (BMS-908662) alone or in combination with cetuximab in subjects with K-RAS or BRAF mutated advanced or metastatic colorectal cancer has been completed which was registered (ID: NCT01086267) with ClinicalTrials.gov. The result of that clinical trial is not yet available.

\subsubsection{Toxicities}

The common adverse effects associated with the drug treatment were fatigue, nausea, vomiting, diarrhoea, anorexia and hypokalaemia [111].

\subsection{RAF265}

\subsubsection{Preclinical study}

RAF265 is a multi-kinase inhibitor which is able to inhibit wild-type BRAF, V600E mutated BRAF as well as CRAF $\left(\mathrm{IC}_{50}=3-60 \mathrm{nM}\right)$. The $\mathrm{EC}_{50}$ for V600E mutated BRAF is $0.14 \mu \mathrm{M}$. It is also able to inhibit VEGFR2 $\left(\mathrm{IC}_{50}=30 \mathrm{nM}, \mathrm{EC}_{50}=0.19 \mu \mathrm{M}\right)$, c-Kit and PDGFR $\beta[28,112]$. In the preclinical study of RAF265 which was done by implanting metastatic melanoma from patients to nude mice, 7 patient explants (41\%) out of 17 explants responded to RAF265 treatment by more than 50\% reduction of melanoma growth where 5 explants bore wild-type BRAF and 2 patients bore BRAF V600E/K mutation. The 
responders showed reduced phosphorylated-MEK1, reduced proliferation as well as induction of apoptosis, but response did not correlate with phosphorylated-ERK1/2 reduction [113].

\subsubsection{Clinical trials}

In the Phase-I clinical trial of RAF265 which was conducted on advanced cutaneous melanoma patients, a total of 76 patients participated [112]. The maximum tolerable dose determined in that trial was 48 mg daily. 10 patients (including 6 BRAF mutant and 3 BRAF wild-type patients) showed overall response.

RAF265 is currently in Phase-II clinical trial on patients with advanced or metastatic melanoma which is registered (ID: NCT00304525) with ClinicalTrials.gov.

\subsubsection{Toxicities}

Common toxicities associated with RAF265 treatment were diarrhoea, ataxia, thrombocytopenia, hyperlipasemia, visual disturbance and pulmonary embolism [112].

\section{Unclassified BRAF inhibitor}

\subsection{ARQ736}

\subsubsection{Preclinical study}

ARQ736 is a potent ATP-competitive inhibitor of V600E mutant BRAF. It is able to kill cancer cell lines that bear at least one allele of mutant BRAF. It is also able to inhibit wild-type BRAF as well as CRAF which was tested in different cell lines like melanoma, colorectal cancer and thyroid cancer cell lines [114, 115]. In addition, ARQ736 showed significant growth inhibition both in melanoma (A375) cell line as well as xenograft model of that cell line. It showed $54 \%$ growth inhibition in that melanoma xenograft model at a dose 
of $300 \mathrm{mg} / \mathrm{kg}$. It also showed reduction of human angiogenesis and cytokine related proteins in a separate experiment in a mouse model $[114,115]$.

\subsubsection{Clinical trials}

A Phase-I clinical trial of ARQ736 in patients with advanced solid tumors harbouring BRAF and/or N-Ras mutations has been completed which was registered (ID: NCT01225536) with ClinicalTrials.gov. The result of that clinical trial is not currently available.

\section{Conclusion}

Type-I BRAF inhibitors are more specific for inhibition of BRAF kinase when compared with type-II BRAF inhibitors. In addition, response rates of type-I BRAF inhibitors are also much higher as compared to type-II BRAF inhibitors. Whether this is a direct result of a superior inhibition capacity or a dilution of the effect of type-II inhibitor effects due to their common inhibition of multiple kinases is an interesting area for future study. Both types of BRAF inhibitors display toxicities that are a great concern, however, especially the development of squamous cell carcinoma and basal cell carcinoma as well as other severe toxicities. In addition, almost half of the patients do not respond to BRAF inhibitor therapy, even for the most effective drugs, which is somewhat disappointing. Moreover, median progression free survivals resulting from the use of the BRAF inhibitors are not satisfactory.

Failure of BRAF inhibitor therapy to show the expected result is also attributed to the development of resistant through reactivation of the same BRAF pathway or activation of alternative pathways for proliferation and survival [17, 41, 116]. BRAF inhibitor resistance 
are found to happen due to any one or combine action of elevated CRAF expression, mutant $B R A F$ amplification, splice variant of mutant $B R A F, N R A S$ mutation, $C R A F$ mutation, $M E K$ mutation, Phosphatase and tensin homolog (PTEN) mutation, hepatocyte growth factor (HGF) overexpression, Cyclin D1 overexpression, cancer Osaka thyroid (COT) overexpression, epidermal growth factor receptor (EGFR) feedback activation, HER3 (v-erbb2 avian erythroblastic leukemia viral oncogene homolog 3) feedback activation, plateletderived growth factor receptor- $\beta$ (PDGFR $\beta$ ) overexpression, insulin-like growth factor 1 receptor (IGF-1R) overexpression, activation of EGFR-SFK-STAT3 signalling pathway or overexpression of ATP-binding cassette (ABC) transporters [17, 41, 116-124].

Therefore, there is a need for more new drugs to be developed as well as research into the modification of existing BRAF inhibitors to improve target specificity and inhibition, to increase the response rates as much as possible while reducing the toxicities as much as possible. This in turn should help to extend the progression free survival times as much as possible. Alternative strategies might include combining these inhibitors with other drugs to cause synergistic effects and allow lower doses with less toxicity to be used while still maintaining strong anti-cancer effects. Such combinations could be determined on an semiindividualised basis through identification of molecular markers of drug resistance, which are now becoming known through mutational studies. Such multi-drug treatments, combined with serial improvements in inhibitor function and toxicity profiles should allow BRAF inhibitors to become an ever more useful part of our anti-cancer armamentarium.

\section{Acknowledgement}

The authors would like to thank Md. Ahad Ali Khan for his help during the manuscript preparation. 


\section{Conflict of Interest Statement}

The authors would like to state that they have no conflict of interest in the publication of this work. 


\section{References}

[1] Moelling K, Heimann B, Beimling P, Rapp UR, et al. Serine- and threonine-specific protein kinase activities of purified gag-mil and gag-raf proteins. Nature $1984 ; 312: 558-61$.

[2] Rapp UR, Goldsborough MD, Mark GE, Bonner TI, et al. Structure and biological activity of v-raf, a unique oncogene transduced by a retrovirus. Proceedings of the National Academy of Sciences of the United States of America 1983;80:4218-22.

[3] Zebisch A, Troppmair J. Back to the roots: the remarkable RAF oncogene story. Cellular and Molecular Life Sciences 2006;63:1314-30.

[4] Rahman MA, Salajegheh A, Smith RA, Lam AKY. B-Raf mutation: A key player in molecular biology of cancer. Experimental and Molecular Pathology 2013:(In Press).

[5] Bonner TI, Kerby SB, Sutrave P, Gunnell MA, et al. Structure and biological activity of human homologs of the raf/mil oncogene. Molecular and cellular biology 1985;5:1400-7.

[6] Huebner K, ar-Rushdi A, Griffin CA, Isobe M, et al. Actively transcribed genes in the raf oncogene group, located on the X chromosome in mouse and human. Proceedings of the National Academy of Sciences of the United States of America 1986;83:39348.

[7] Ikawa S, Fukui M, Ueyama Y, Tamaoki N, et al. B-raf, a new member of the raf family, is activated by DNA rearrangement. Molecular and cellular biology 1988;8:2651-4.

[8] Roskoski JR. RAF protein-serine/threonine kinases: structure and regulation. Biochemical and biophysical research communications 2010;399:313-7. 
[9] Barnier JV, Papin C, Eychene A, Lecoq O, et al. The mouse B-raf gene encodes multiple protein isoforms with tissue-specific expression. The Journal of biological chemistry 1995;270:23381-9.

[10] Storm SM, Cleveland JL, Rapp UR. Expression of raf family proto-oncogenes in normal mouse tissues. Oncogene 1990;5:345-51.

[11] Wellbrock C, Karasarides M. The RAF proteins take centre stage. Nature Reviews Molecular Cell Biology 2004;5:875-85.

[12] Cantwell-Dorris ER, O'Leary JJ, Sheils OM. BRAFV600E: implications for carcinogenesis and molecular therapy. Molecular cancer therapeutics 2011;10:385-94.

[13] Johnson LN, Lowe ED, Noble ME, Owen DJ. The Eleventh Datta Lecture. The structural basis for substrate recognition and control by protein kinases. FEBS letters 1998;430:1-11.

[14] Garnett MJ, Marais R. Guilty as charged: B-RAF is a human oncogene. Cancer cell 2004;6:313-9.

[15] Wan PT, Garnett MJ, Roe SM, Lee S, et al. Mechanism of activation of the RAFERK signaling pathway by oncogenic mutations of B-RAF. Cell 2004;116:855-67.

[16] Davies H, Bignell GR, Cox C, Stephens P, et al. Mutations of the BRAF gene in human cancer. Nature 2002;417:949-54.

[17] Rahman MA, Salajegheh A, Smith RA, Lam AKY. BRAF inhibitor therapy for melanoma, thyroid and colorectal cancers: development of resistance and future prospects. Current cancer drug targets 2013:(In Press).

[18] Pakneshan S, Salajegheh A, Smith RA, Lam AK. Clinicopathological relevance of BRAF mutations in human cancer. Pathology 2013;45:346-56. 
[19] Long GV, Menzies AM, Nagrial AM, Haydu LE, et al. Prognostic and clinicopathologic associations of oncogenic BRAF in metastatic melanoma. J Clin Oncol 2011;29:1239-46.

[20] Kim TH, Park YJ, Lim JA, Ahn HY, et al. The association of the BRAF(V600E) mutation with prognostic factors and poor clinical outcome in papillary thyroid cancer: a meta-analysis. Cancer 2012;118:1764-73.

[21] Salajegheh A, Pakneshan S, Rahman A, Dolan-Evans E, et al. Co-regulatory potential of vascular endothelial growth factor-A and vascular endothelial growth factor-C in thyroid carcinoma. Hum Pathol 2013;44:2204-12.

[22] El-Osta H, Falchook G, Tsimberidou A, Hong D, et al. BRAF mutations in advanced cancers: clinical characteristics and outcomes. PLoS One 2011;6:e25806.

[23] Lee S, Cho NY, Choi M, Yoo EJ, et al. Clinicopathological features of CpG island methylator phenotype-positive colorectal cancer and its adverse prognosis in relation to KRAS/BRAF mutation. Pathology international 2008;58:104-13.

[24] Manning G, Whyte DB, Martinez R, Hunter T, et al. The protein kinase complement of the human genome. Science (New York, NY) 2002;298:1912-34.

[25] Hunter T. The role of tyrosine phosphorylation in cell growth and disease. Harvey lectures 1998;94:81-119.

[26] Cohen P. Protein kinases--the major drug targets of the twenty-first century? Nature reviews Drug discovery 2002;1:309-15.

[27] Liu Y, Gray NS. Rational design of inhibitors that bind to inactive kinase conformations. Nature chemical biology 2006;2:358-64.

[28] Zambon A, Niculescu-Duvaz I, Niculescu-Duvaz D, Marais R, et al. Small molecule inhibitors of BRAF in clinical trials. Bioorganic \& medicinal chemistry letters 2012;22:789-92. 
[29] Traxler P, Furet P. Strategies toward the design of novel and selective protein tyrosine kinase inhibitors. Pharmacology \& therapeutics 1999;82:195-206.

[30] Zhang J, Yang PL, Gray NS. Targeting cancer with small molecule kinase inhibitors. Nature reviews Cancer 2009;9:28-39.

[31] Mol CD, Fabbro D, Hosfield DJ. Structural insights into the conformational selectivity of STI-571 and related kinase inhibitors. Current opinion in drug discovery \& development 2004;7:639-48.

[32] Pargellis C, Tong L, Churchill L, Cirillo PF, et al. Inhibition of p38 MAP kinase by utilizing a novel allosteric binding site. Nature structural biology 2002;9:268-72.

[33] Schindler T, Bornmann W, Pellicena P, Miller WT, et al. Structural mechanism for STI-571 inhibition of abelson tyrosine kinase. Science (New York, NY) 2000;289:1938-42.

[34] Yang H, Higgins B, Kolinsky K, Packman K, et al. RG7204 (PLX4032), a selective BRAFV600E inhibitor, displays potent antitumor activity in preclinical melanoma models. Cancer research 2010;70:5518-27.

[35] Tap WD, Gong KW, Dering J, Tseng Y, et al. Pharmacodynamic characterization of the efficacy signals due to selective BRAF inhibition with PLX4032 in malignant melanoma. Neoplasia (New York, NY) 2010;12:637-49.

[36] Bollag G, Hirth P, Tsai J, Zhang J, et al. Clinical efficacy of a RAF inhibitor needs broad target blockade in BRAF-mutant melanoma. Nature 2010;467:596-9.

[37] Flaherty KT, Puzanov I, Kim KB, Ribas A, et al. Inhibition of mutated, activated BRAF in metastatic melanoma. The New England journal of medicine 2010;363:80919. 
[38] Kim KB, Flaherty KT, Chapman PB, Sosman JA, et al. Pattern and outcome of disease progression in phase I study of vemurafenib in patients with metastatic melanoma (MM). J Clin Oncol 2011;29:(suppl; abstr 8519).

[39] Alcala AM, Flaherty KT. BRAF inhibitors for the treatment of metastatic melanoma: clinical trials and mechanisms of resistance. Clinical cancer research : an official journal of the American Association for Cancer Research 2012;18:33-9.

[40] Ribas A, Kim KB, Schuchter LM, Gonzalez R, et al. BRIM-2: An open-label, multicenter phase II study of vemurafenib in previously treated patients with BRAF V600E mutation-positive metastatic melanoma. J Clin Oncol 2011;29:(suppl; abstr 8509).

[41] Trunzer K, Pavlick AC, Schuchter L, Gonzalez R, et al. Pharmacodynamic effects and mechanisms of resistance to vemurafenib in patients with metastatic melanoma. J Clin Oncol 2013;31:1767-74.

[42] Ravnan MC, Matalka MS. Vemurafenib in patients with BRAF V600E mutationpositive advanced melanoma. Clinical therapeutics 2012;34:1474-86.

[43] Chapman PB, Hauschild A, Robert C, Haanen JB, et al. Improved survival with vemurafenib in melanoma with BRAF V600E mutation. The New England journal of medicine 2011;364:2507-16.

[44] da Rocha Dias S, Salmonson T, van Zwieten-Boot B, Jonsson B, et al. The European Medicines Agency review of vemurafenib (Zelboraf(R)) for the treatment of adult patients with BRAF V600 mutation-positive unresectable or metastatic melanoma: summary of the scientific assessment of the Committee for Medicinal Products for Human Use. European journal of cancer (Oxford, England : 1990) 2013;49:1654-61. 
[45] Mattei PL, Alora-Palli MB, Kraft S, Lawrence DP, et al. Cutaneous effects of BRAF inhibitor therapy: a case series. Annals of oncology : official journal of the European Society for Medical Oncology / ESMO 2013;24:530-7.

[46] Anforth R, Fernandez-Penas P, Long GV. Cutaneous toxicities of RAF inhibitors. The lancet oncology 2013;14:e11-8.

[47] Laquerre SG, Arnone M, Moss K, Yang J, et al. A selective Raf kinase inhibitor induces cell death and tumor regression of human cancer cell lines encoding BRafV600E mutation. Molecular cancer therapeutics 2009;8:(12 Suppl: Abstract B88).

[48] Gibney GT, Zager JS. Clinical development of dabrafenib in BRAF mutant melanoma and other malignancies. Expert opinion on drug metabolism \& toxicology 2013;9:893-9.

[49] Gentilcore G, Madonna G, Mozzillo N, Ribas A, et al. Effect of dabrafenib on melanoma cell lines harbouring the BRAF(V600D/R) mutations. BMC cancer 2013;13:17.

[50] Falchook GS, Long GV, Kurzrock R, Kim KB, et al. Dabrafenib in patients with melanoma, untreated brain metastases, and other solid tumours: a phase 1 doseescalation trial. Lancet 2012;379:1893-901.

[51] Menzies AM, Long GV, Murali R. Dabrafenib and its potential for the treatment of metastatic melanoma. Drug design, development and therapy 2012;6:391-405.

[52] Trefzer U, Minor D, Ribas A, Et al. BREAK-2: a phase IIA trial of the selective BRAF kinase inhibitor GSK2118436 in patients with BRAF mutation-positive (V600E/K) metastatic melanoma. Pigment Cell Melanoma Res 2011;24:1020 (Abstr LBA1-1). 
[53] Long GV, Trefzer U, Davies MA, Kefford RF, et al. Dabrafenib in patients with Val600Glu or Val600Lys BRAF-mutant melanoma metastatic to the brain (BREAKMB): a multicentre, open-label, phase 2 trial. The lancet oncology 2012;13:1087-95.

[54] Hauschild A, Grob JJ, Demidov LV, Jouary T, et al. Dabrafenib in BRAF-mutated metastatic melanoma: a multicentre, open-label, phase 3 randomised controlled trial. Lancet 2012;380:358-65.

[55] http://www.fda.gov/Drugs/InformationOnDrugs/ApprovedDrugs/ucm354477.htm.

[56] Anforth RM, Blumetti TC, Kefford RF, Sharma R, et al. Cutaneous manifestations of dabrafenib (GSK2118436): a selective inhibitor of mutant BRAF in patients with metastatic melanoma. The British journal of dermatology 2012;167:1153-60.

[57] Stuart DD, Li N, Poon DJ, Aardalen K, et al. Preclinical profile of LGX818: A potent and selective RAF kinase inhibitor. Cancer research 2012;72:(8 Suppl : Abstract 3790).

[58] Tsai J, Lee JT, Wang W, Zhang J, et al. Discovery of a selective inhibitor of oncogenic B-Raf kinase with potent antimelanoma activity. Proceedings of the National Academy of Sciences of the United States of America 2008;105:3041-6.

[59] Nucera C, Nehs MA, Nagarkatti SS, Sadow PM, et al. Targeting BRAFV600E with PLX4720 displays potent antimigratory and anti-invasive activity in preclinical models of human thyroid cancer. The oncologist 2011;16:296-309.

[60] King AJ, Patrick DR, Batorsky RS, Ho ML, et al. Demonstration of a genetic therapeutic index for tumors expressing oncogenic BRAF by the kinase inhibitor SB590885. Cancer research 2006;66:11100-5.

[61] Takle AK, Brown MJ, Davies S, Dean DK, et al. The identification of potent and selective imidazole-based inhibitors of B-Raf kinase. Bioorganic \& medicinal chemistry letters 2006;16:378-81. 
[62] Hoeflich KP, Herter S, Tien J, Wong L, et al. Antitumor efficacy of the novel RAF inhibitor GDC-0879 is predicted by BRAFV600E mutational status and sustained extracellular signal-regulated kinase/mitogen-activated protein kinase pathway suppression. Cancer research 2009;69:3042-51.

[63] Hansen JD, Grina J, Newhouse B, Welch M, et al. Potent and selective pyrazolebased inhibitors of B-Raf kinase. Bioorganic \& medicinal chemistry letters 2008;18:4692-5.

[64] Wilhelm S, Chien DS. BAY 43-9006: preclinical data. Current pharmaceutical design 2002;8:2255-7.

[65] Strumberg D, Clark JW, Awada A, Moore MJ, et al. Safety, pharmacokinetics, and preliminary antitumor activity of sorafenib: a review of four phase I trials in patients with advanced refractory solid tumors. The oncologist 2007;12:426-37.

[66] Wilhelm SM, Carter C, Tang L, Wilkie D, et al. BAY 43-9006 exhibits broad spectrum oral antitumor activity and targets the RAF/MEK/ERK pathway and receptor tyrosine kinases involved in tumor progression and angiogenesis. Cancer research 2004;64:7099-109.

[67] Levy JB, Pauloski N, Braun D, Derome M, et al. Analysis of transcription and protein expression changes in the 786-O human renal cell carcinoma tumor xenograft model in response to treatment with the multi-kinase inhibitor sorafenib (BAY 43-9006). Proc Amer Assoc Cancer Res 2006;47:213-4 (Abstract \# 906).

[68] Carlomagno F, Anaganti S, Guida T, Salvatore G, et al. BAY 43-9006 inhibition of oncogenic RET mutants. Journal of the National Cancer Institute 2006;98:326-34.

[69] Wilhelm S, Carter C, Lynch M, Lowinger T, et al. Discovery and development of sorafenib: a multikinase inhibitor for treating cancer. Nature reviews Drug discovery 2006;5:835-44. 
[70] Clark JW, Eder JP, Ryan D, Lathia C, et al. Safety and pharmacokinetics of the dual action Raf kinase and vascular endothelial growth factor receptor inhibitor, BAY 439006, in patients with advanced, refractory solid tumors. Clinical cancer research : an official journal of the American Association for Cancer Research 2005;11:5472-80.

[71] Awada A, Hendlisz A, Gil T, Bartholomeus S, et al. Phase I safety and pharmacokinetics of BAY 43-9006 administered for 21 days on/7 days off in patients with advanced, refractory solid tumours. British journal of cancer 2005;92:1855-61.

[72] Moore M, Hirte HW, Siu L, Oza A, et al. Phase I study to determine the safety and pharmacokinetics of the novel Raf kinase and VEGFR inhibitor BAY 43-9006, administered for 28 days on/7 days off in patients with advanced, refractory solid tumors. Annals of oncology : official journal of the European Society for Medical Oncology / ESMO 2005;16:1688-94.

[73] Strumberg D, Richly H, Hilger RA, Schleucher N, et al. Phase I clinical and pharmacokinetic study of the Novel Raf kinase and vascular endothelial growth factor receptor inhibitor BAY 43-9006 in patients with advanced refractory solid tumors. J Clin Oncol 2005;23:965-72.

[74] Eisen T, Ahmad T, Flaherty KT, Gore M, et al. Sorafenib in advanced melanoma: a Phase II randomised discontinuation trial analysis. British journal of cancer 2006;95:581-6.

[75] Kloos RT, Ringel MD, Knopp MV, Hall NC, et al. Phase II trial of sorafenib in metastatic thyroid cancer. J Clin Oncol 2009;27:1675-84.

[76] Lam ET, Ringel MD, Kloos RT, Prior TW, et al. Phase II clinical trial of sorafenib in metastatic medullary thyroid cancer. J Clin Oncol 2010;28:2323-30. 
[77] Savvides P, Nagaiah G, Lavertu P, Fu P, et al. Phase II trial of sorafenib in patients with advanced anaplastic carcinoma of the thyroid. Thyroid : official journal of the American Thyroid Association 2013;23:600-4.

[78] Ratain MJ, Eisen T, Stadler WM, Flaherty KT, et al. Phase II placebo-controlled randomized discontinuation trial of sorafenib in patients with metastatic renal cell carcinoma. J Clin Oncol 2006;24:2505-12.

[79] Bengala C, Bertolini F, Malavasi N, Boni C, et al. Sorafenib in patients with advanced biliary tract carcinoma: a phase II trial. British journal of cancer 2010;102:68-72.

[80] Bianchi G, Loibl S, Zamagni C, Salvagni S, et al. Phase II multicenter, uncontrolled trial of sorafenib in patients with metastatic breast cancer. Anti-cancer drugs 2009;20:616-24.

[81] Safarinejad MR. Safety and efficacy of sorafenib in patients with castrate resistant prostate cancer: a Phase II study. Urologic oncology 2010;28:21-7.

[82] Rimassa L, Pressiani T, Boni C, Carnaghi C, et al. A phase II randomized dose escalation trial of sorafenib in patients with advanced hepatocellular carcinoma. The oncologist 2013;18:379-80.

[83] Dy GK, Hillman SL, Rowland KM, Jr., Molina JR, et al. A front-line window of opportunity phase 2 study of sorafenib in patients with advanced nonsmall cell lung cancer: North Central Cancer Treatment Group Study N0326. Cancer 2010;116:568693.

[84] Llovet JM, Ricci S, Mazzaferro V, Hilgard P, et al. Sorafenib in advanced hepatocellular carcinoma. The New England journal of medicine 2008;359:378-90.

[85] Escudier B, Eisen T, Stadler WM, Szczylik C, et al. Sorafenib for treatment of renal cell carcinoma: Final efficacy and safety results of the phase III treatment approaches in renal cancer global evaluation trial. J Clin Oncol 2009;27:3312-8. 
[86] Brose MS, Nutting CM, Sherman SI, Shong YK, et al. Rationale and design of decision: a double-blind, randomized, placebo-controlled phase III trial evaluating the efficacy and safety of sorafenib in patients with locally advanced or metastatic radioactive iodine (RAI)-refractory, differentiated thyroid cancer. BMC cancer 2011;11:349.

[87] Kudo M, Imanaka K, Chida N, Nakachi K, et al. Phase III study of sorafenib after transarterial chemoembolisation in Japanese and Korean patients with unresectable hepatocellular carcinoma. European journal of cancer (Oxford, England : 1990) 2011;47:2117-27.

[88] Cheng AL, Kang YK, Chen Z, Tsao CJ, et al. Efficacy and safety of sorafenib in patients in the Asia-Pacific region with advanced hepatocellular carcinoma: a phase III randomised, double-blind, placebo-controlled trial. The lancet oncology 2009;10:25-34.

[89] Rimassa L, Santoro A. Sorafenib therapy in advanced hepatocellular carcinoma: the SHARP trial. Expert review of anticancer therapy 2009;9:739-45.

[90] Brose MS, Nutting C, Jarzab B, Elisei R, et al. Sorafenib in locally advanced or metastatic patients with radioactive iodine-refractory differentiated thyroid cancer: The phase III DECISION trial. J Clin Oncol 2013;31:(suppl; abstr 4).

[91] Whittaker S, Kirk R, Hayward R, Zambon A, et al. Gatekeeper mutations mediate resistance to BRAF-targeted therapies. Science translational medicine 2010;2:35ra41.

[92] Liu L, Cao Y, Chen C, Zhang X, et al. Sorafenib blocks the RAF/MEK/ERK pathway, inhibits tumor angiogenesis, and induces tumor cell apoptosis in hepatocellular carcinoma model PLC/PRF/5. Cancer research 2006;66:11851-8. 
[93] Lierman E, Folens C, Stover EH, Mentens N, et al. Sorafenib is a potent inhibitor of FIP1L1-PDGFRalpha and the imatinib-resistant FIP1L1-PDGFRalpha T674I mutant. Blood 2006;108:1374-6.

[94] Guo T, Agaram NP, Wong GC, Hom G, et al. Sorafenib inhibits the imatinib-resistant KITT670I gatekeeper mutation in gastrointestinal stromal tumor. Clinical cancer research : an official journal of the American Association for Cancer Research 2007;13:4874-81.

[95] Sherman SI. Molecularly targeted therapies for thyroid cancers. Endocrine practice : official journal of the American College of Endocrinology and the American Association of Clinical Endocrinologists 2009;15:605-11.

[96] Dubauskas Z, Kunishige J, Prieto VG, Jonasch E, et al. Cutaneous squamous cell carcinoma and inflammation of actinic keratoses associated with sorafenib. Clinical genitourinary cancer 2009;7:20-3.

[97] Wilhelm SM, Dumas J, Adnane L, Lynch M, et al. Regorafenib (BAY 73-4506): a new oral multikinase inhibitor of angiogenic, stromal and oncogenic receptor tyrosine kinases with potent preclinical antitumor activity. International journal of cancer Journal international du cancer 2011;129:245-55.

[98] Strumberg D, Scheulen ME, Schultheis B, Richly H, et al. Regorafenib (BAY 734506) in advanced colorectal cancer: a phase I study. British journal of cancer 2012;106:1722-7.

[99] Mross K, Frost A, Steinbild S, Hedbom S, et al. A phase I dose-escalation study of regorafenib (BAY 73-4506), an inhibitor of oncogenic, angiogenic, and stromal kinases, in patients with advanced solid tumors. Clinical cancer research : an official journal of the American Association for Cancer Research 2012;18:2658-67. 
[100] Sunakawa Y, Furuse J, Okusaka T, Ikeda M, et al. Regorafenib in Japanese patients with solid tumors: phase I study of safety, efficacy, and pharmacokinetics. Investigational new drugs 2013.

[101] George S, Wang Q, Heinrich MC, Corless CL, et al. Efficacy and safety of regorafenib in patients with metastatic and/or unresectable GI stromal tumor after failure of imatinib and sunitinib: a multicenter phase II trial. J Clin Oncol 2012;30:2401-7.

[102] Eisen T, Joensuu H, Nathan PD, Harper PG, et al. Regorafenib for patients with previously untreated metastatic or unresectable renal-cell carcinoma: a single-group phase 2 trial. The lancet oncology 2012;13:1055-62.

[103] Bruix J, Tak WY, Gasbarrini A, Santoro A, et al. Regorafenib as second-line therapy for intermediate or advanced hepatocellular carcinoma: Multicentre, open-label, phase II safety study. European journal of cancer (Oxford, England : 1990) 2013.

[104] Grothey A, Van Cutsem E, Sobrero A, Siena S, et al. Regorafenib monotherapy for previously treated metastatic colorectal cancer (CORRECT): an international, multicentre, randomised, placebo-controlled, phase 3 trial. Lancet 2013;381:303-12.

[105] Demetri GD, Reichardt P, Kang YK, Blay JY, et al. Efficacy and safety of regorafenib for advanced gastrointestinal stromal tumours after failure of imatinib and sunitinib (GRID): an international, multicentre, randomised, placebo-controlled, phase 3 trial. Lancet 2013;381:295-302.

[106] FDA approves regorafenib (Stivarga) for metastatic colorectal cancer. Oncology (Williston Park, NY) 2012;26:896.

[107] FDA approves regorafenib (Stivarga) for GIST. Oncology (Williston Park, NY) 2013;27:164. 
[108] Zaki K, Aslam S, Eisen T. Regorafenib (BAY 73-4506): Stromal and Oncogenic Multikinase Inhibitor with Potential Activity in Renal Cell Carcinoma. Current oncology reports 2013.

[109] Cutsem EV, Sobrero AF, Siena S, Falcone A, et al. Phase III CORRECT trial of regorafenib in metastatic colorectal cancer (mCRC). J Clin Oncol 2012;30:(suppl; abstr 3502).

[110] Ribas A, Flaherty KT. BRAF targeted therapy changes the treatment paradigm in melanoma. Nature reviews Clinical oncology 2011;8:426-33.

[111] Schwartz GK, Robertson S, Shen A, Wang E, et al. A phase I study of XL281, a selective oral RAF kinase inhibitor, in patients (Pts) with advanced solid tumors. J Clin Oncol 2009;27:15s:(suppl; abstr 3513).

[112] Sharfman WH, Hodi FS, Lawrence DP, Flaherty KT, et al. Results from the first-inhuman (FIH) phase I study of the oral RAF inhibitor RAF265 administered daily to patients with advanced cutaneous melanoma. J Clin Oncol 2011;29:(suppl; abstr 8508).

[113] Su Y, Vilgelm AE, Kelley MC, Hawkins OE, et al. RAF265 inhibits the growth of advanced human melanoma tumors. Clinical cancer research : an official journal of the American Association for Cancer Research 2012;18:2184-98.

[114] Yu Y, Zhao X, Gu X, Chang E, et al. Pharmacodynamic biomarkers for ARQ736, a small molecule BRAF inhibitor. Cancer research 2010;70:(8 Suppl : Abstract 2517).

[115] Huang T, Karsy M, Zhuge J, Zhong M, et al. B-Raf and the inhibitors: from bench to bedside. Journal of hematology \& oncology 2013;6:30.

[116] Corcoran RB, Settleman J, Engelman JA. Potential therapeutic strategies to overcome acquired resistance to BRAF or MEK inhibitors in BRAF mutant cancers. Oncotarget 2011;2:336-46. 
[117] Smalley KS, Lioni M, Dalla Palma M, Xiao M, et al. Increased cyclin D1 expression can mediate BRAF inhibitor resistance in BRAF V600E-mutated melanomas. Molecular cancer therapeutics 2008;7:2876-83.

[118] Straussman R, Morikawa T, Shee K, Barzily-Rokni M, et al. Tumour microenvironment elicits innate resistance to RAF inhibitors through HGF secretion. Nature 2012;487:500-4.

[119] Paraiso KH, Xiang Y, Rebecca VW, Abel EV, et al. PTEN loss confers BRAF inhibitor resistance to melanoma cells through the suppression of BIM expression. Cancer research 2011;71:2750-60.

[120] Antony R, Emery CM, Sawyer AM, Garraway LA. C-RAF mutations confer resistance to RAF inhibitors. Cancer research 2013;73:4840-51.

[121] Prahallad A, Sun C, Huang S, Di Nicolantonio F, et al. Unresponsiveness of colon cancer to BRAF(V600E) inhibition through feedback activation of EGFR. Nature 2012;483:100-3.

[122] Montero-Conde C, Ruiz-Llorente S, Dominguez JM, Knauf JA, et al. Relief of feedback inhibition of HER3 transcription by RAF and MEK inhibitors attenuates their antitumor effects in BRAF-mutant thyroid carcinomas. Cancer discovery 2013;3:520-33.

[123] Girotti MR, Pedersen M, Sanchez-Laorden B, Viros A, et al. Inhibiting EGF receptor or SRC family kinase signaling overcomes BRAF inhibitor resistance in melanoma. Cancer discovery 2013;3:158-67.

[124] Wu CP, Sim HM, Huang YH, Liu YC, et al. Overexpression of ATP-binding cassette transporter ABCG2 as a potential mechanism of acquired resistance to vemurafenib in BRAF(V600E) mutant cancer cells. Biochemical pharmacology 2013;85:325-34. 


\section{Figure Legends}

Figure 1: Structure of BRAF kinase domain. Different regions of BRAF kinase domain are indicated with different color: small lobe (light pink), large lobe (light blue), glycine rich loop (pale green), catalytic loop (magenta), DFG motif (red) and activation segment (blue). The image is prepared with PyMOL by using X-ray crystal structure (PDB ID: 4MBJ) from protein data bank.

Figure 2: Structure of BRAF V600E kinase domain in complex with BRAF inhibitor PLX4032 (Vemurafenib). Different regions of BRAF kinase domain are indicated with different color: small lobe (light pink), large lobe (light blue), glycine rich loop (pale green), catalytic loop (magenta) and DFG motif (red). A. Binding pattern of PLX4032 with kinase domain of V600E mutant BRAF. B. Close view of V600E mutant BRAF and PLX4032 complex. The images are prepared with PyMOL by using X-ray crystal structure (PDB ID: 3OG7) from protein data bank.

Figure 3: Structure of BRAF V600E kinase domain in complex with BRAF inhibitor BAY 43-9006 (Sorafenib). Different regions of BRAF kinase domain are indicated with different color: small lobe (light pink), large lobe (light blue), glycine rich loop (pale green), catalytic loop (magenta), DFG motif (red) and activation segment (blue). A. Binding pattern of BAY 43-9006 with kinase domain of V600E mutant BRAF. B. Close view of V600E mutant BRAF and BAY 43-9006 complex. The images are prepared with PyMOL by using X-ray crystal structure (PDB ID: 1UWJ) from protein data bank. 
Figure 1

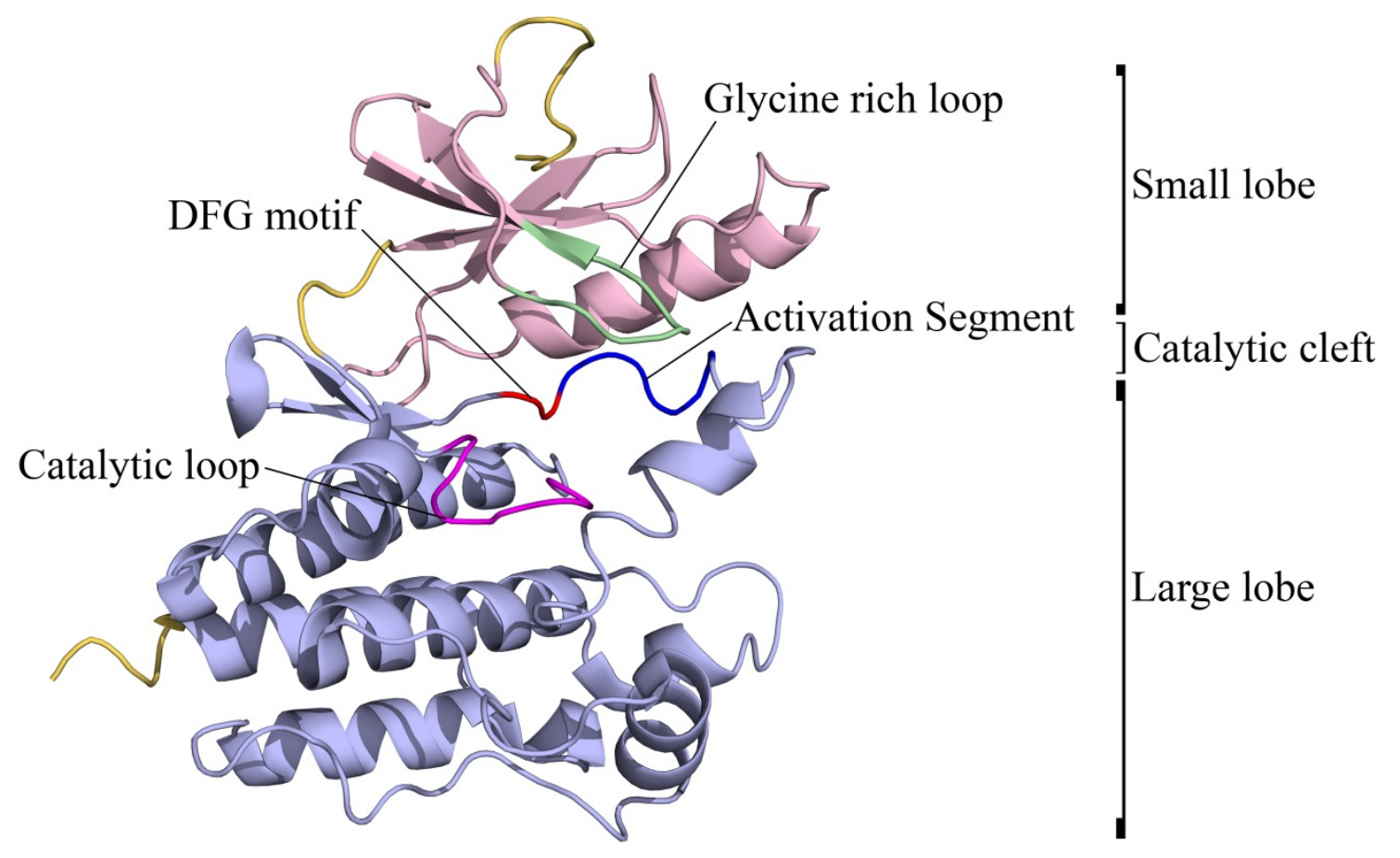


Figure 2A

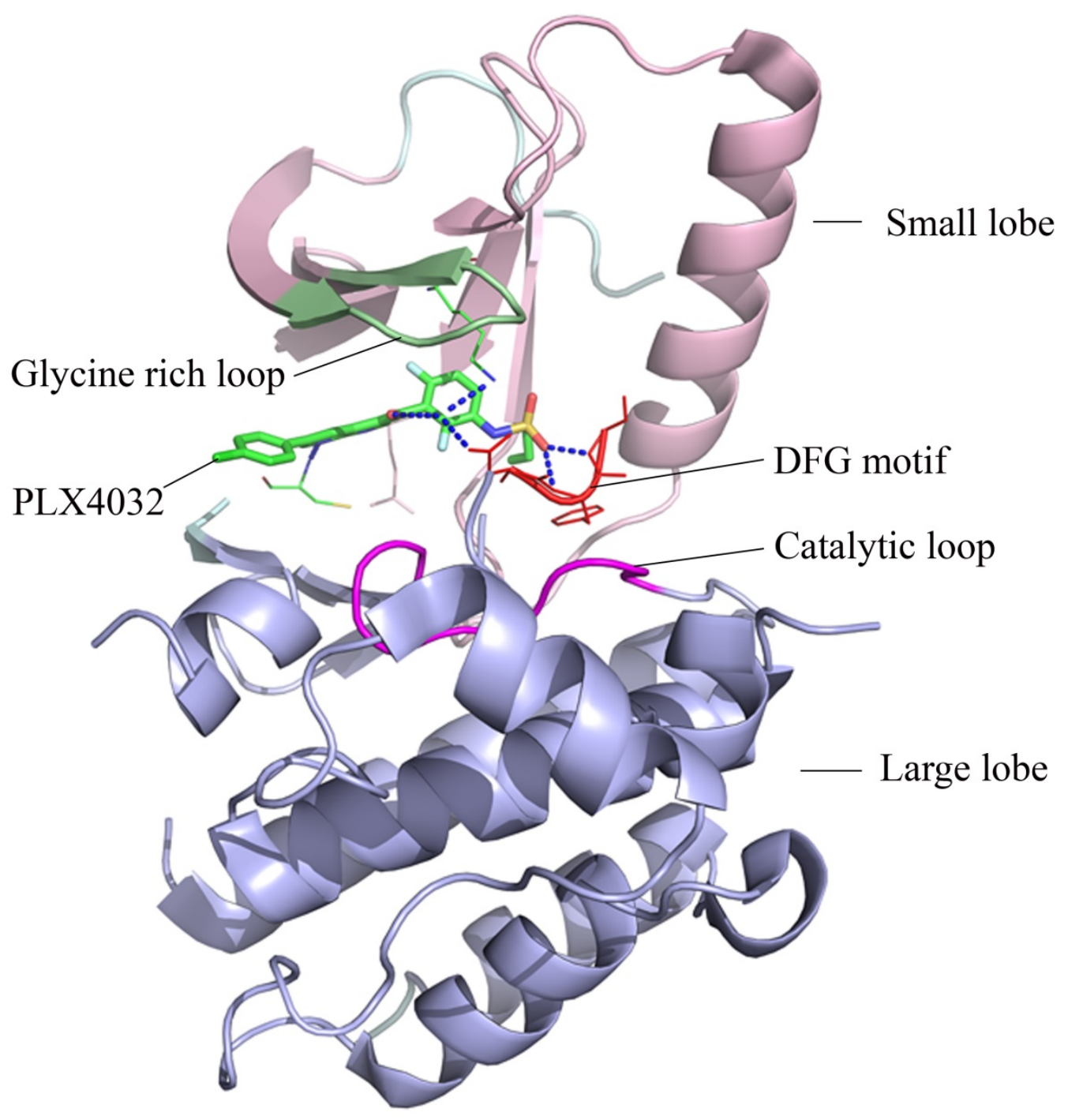


Figure 2B

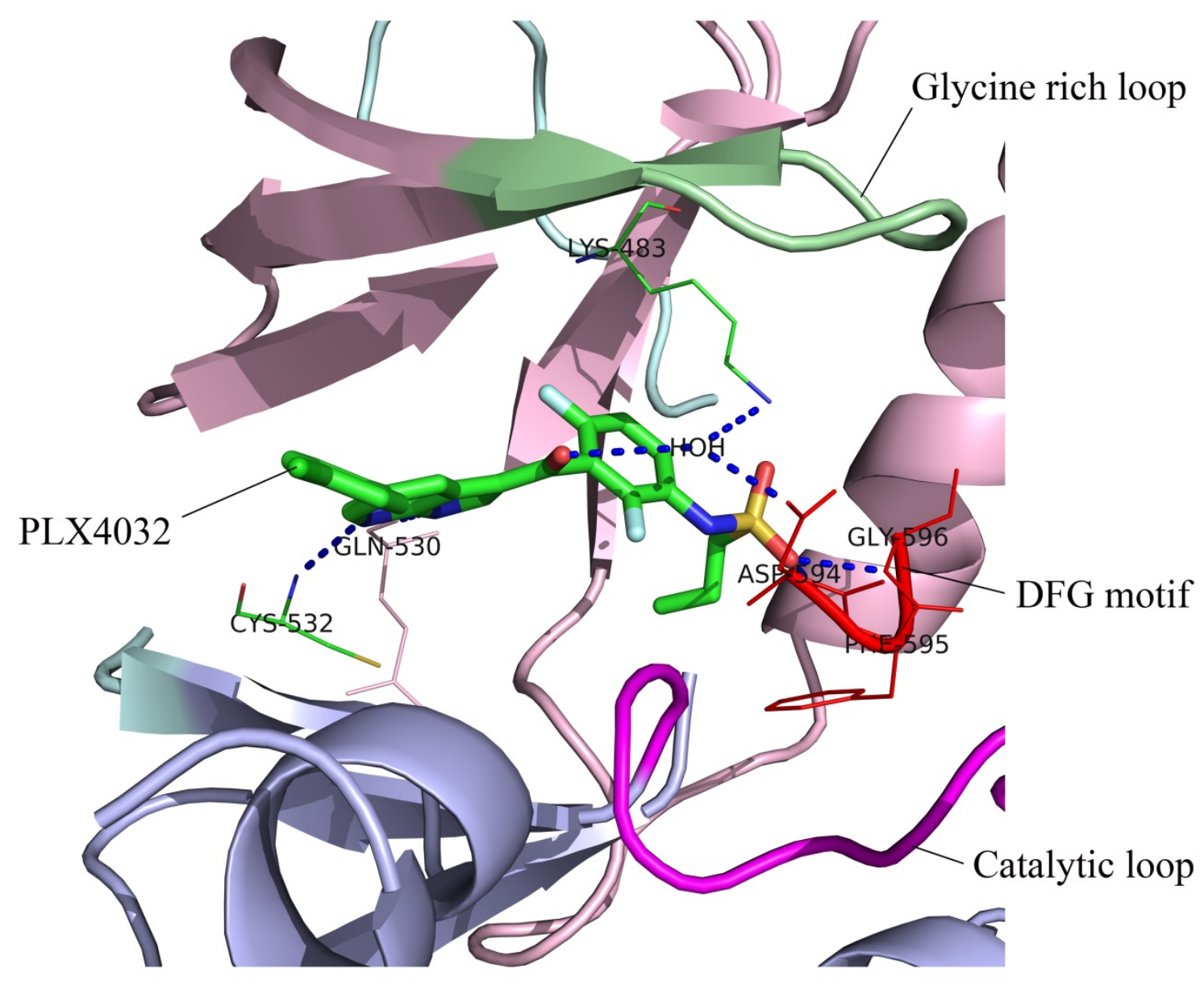


Figure 3A

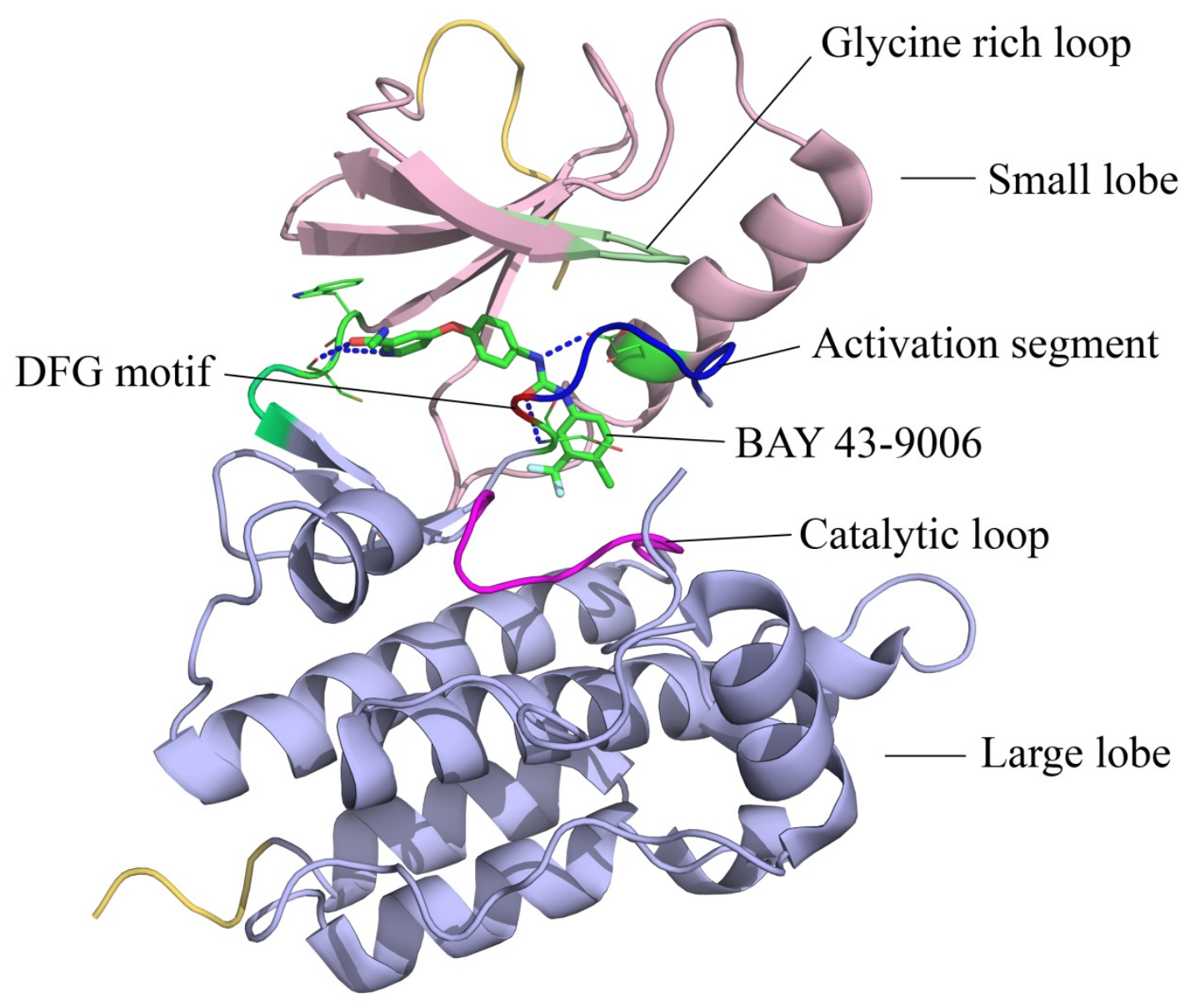


Figure 3B

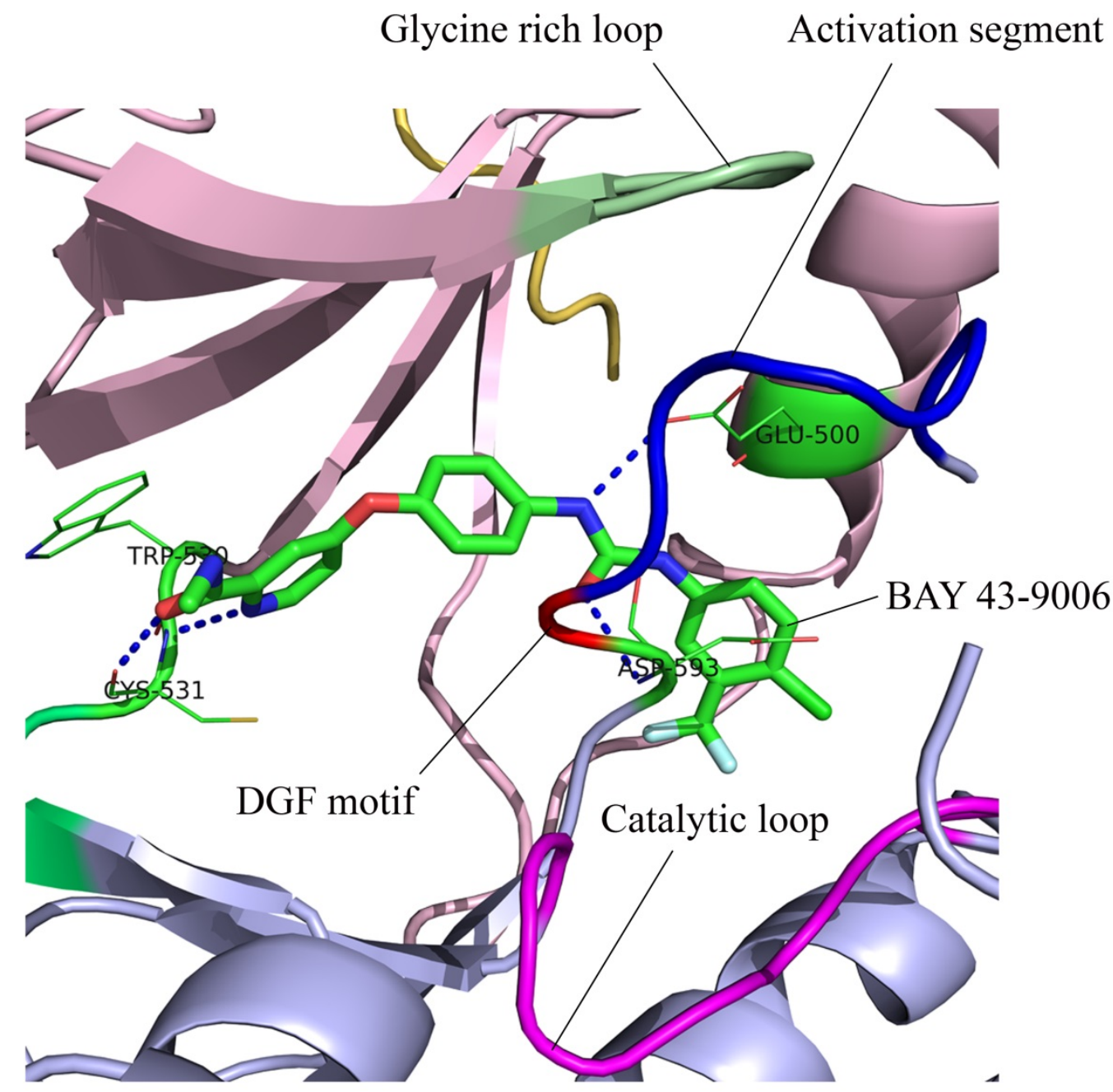


Table 1: Summary of BRAF inhibitors

\begin{tabular}{|c|c|c|c|c|c|c|c|c|c|c|c|c|c|}
\hline \multirow[t]{2}{*}{ Drug } & \multirow[t]{2}{*}{ Type } & \multirow[t]{2}{*}{ Drug Target } & \multirow{2}{*}{ 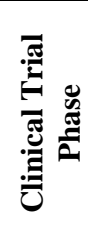 } & \multirow[t]{2}{*}{ Cancer Type } & \multirow[b]{2}{*}{ 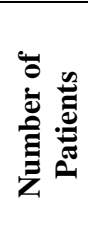 } & \multirow[b]{2}{*}{ 旁 } & \multicolumn{2}{|c|}{$\begin{array}{c}\text { Response Rate } \\
(\%)\end{array}$} & \multirow{2}{*}{ 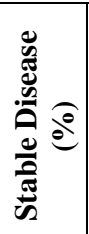 } & \multirow{2}{*}{ 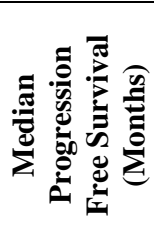 } & \multirow{2}{*}{$\begin{array}{c}\text { Median } \\
\text { Overall } \\
\text { Survival } \\
\text { (Months) }\end{array}$} & \multirow{2}{*}{ 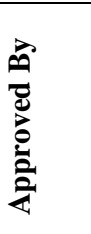 } & \multirow[t]{2}{*}{ References } \\
\hline & & & & & & & 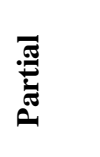 & ن⿺辶ّ & & & & & \\
\hline Vemurafenib & $\mathrm{I}$ & $\mathrm{BRAF}^{\mathrm{V} 600 \mathrm{E}}, \mathrm{BRAF}^{\mathrm{WT}}, \mathrm{CRAF}$ & III & $\begin{array}{l}\text { Metastatic } \\
\text { Melanoma }\end{array}$ & 675 & $\begin{array}{c}960 \\
\text { (b.i.d.) }\end{array}$ & 47.49 & 0.91 & & 6.9 & 13.2 & $\mathrm{FDA}^{\mathrm{a}}$ & {$[43,44]$} \\
\hline Dabrafenib & I & $\mathrm{BRAF}^{\mathrm{V} 600 \mathrm{E}}, \mathrm{BRAF}^{\mathrm{WT}}, \mathrm{CRAF}$ & III & $\begin{array}{l}\text { Metastatic } \\
\text { Melanoma }\end{array}$ & 250 & $\begin{array}{c}150 \\
\text { (b.i.d.) }\end{array}$ & 47 & 3 & 42 & 5.1 & & $\mathrm{FDA}^{\mathrm{a}}$ & [54] \\
\hline LGX818 & $\mathrm{I}$ & BRAF $^{\mathrm{V} 600 \mathrm{E}}$ & $\mathrm{I}$ & $\begin{array}{l}\text { Metastatic } \\
\text { Melanoma }\end{array}$ & & & & & & & & & [57] \\
\hline PLX4720 & $\mathrm{I}$ & $\mathrm{BRAF}^{\mathrm{V} 600 \mathrm{E}}, \mathrm{BRAF}^{\mathrm{WT}}, \mathrm{CRAF}$ & Pre- & & & & & & & & & & {$[58]$} \\
\hline SB-590885 & $\mathrm{I}$ & $\mathrm{BRAF}^{\mathrm{V} 600 \mathrm{E}}, \mathrm{BRAF}^{\mathrm{WT}}, \mathrm{CRAF}$ & Pre- & & & & & & & & & & {$[60]$} \\
\hline GDC-0879 & I & $\mathrm{BRAF}^{\mathrm{V} 600 \mathrm{E}}, \mathrm{BRAF}^{\mathrm{WT}}, \mathrm{CRAF}$ & Pre- & & & & & & & & & & [62] \\
\hline Sorafenib & II & $\begin{array}{l}\text { BRAF }^{\mathrm{V} 600 \mathrm{E}}, \mathrm{BRAF}^{\mathrm{WT}} \text {, CRAF, } \\
\text { RET, c-KIT, Flt-3, VEGFR1, } \\
\text { VEGFR2, FGFR1, p38 }\end{array}$ & III & $\begin{array}{l}\text { Advanced } \\
\text { Hepatocellular } \\
\text { Carcinoma }\end{array}$ & 602 & $\begin{array}{c}400 \\
\text { (b.i.d.) }\end{array}$ & 2 & 0 & 71 & $5.5^{\mathrm{b}}$ & 10.7 & $\mathrm{FDA}^{\mathrm{c}}$ & [84] \\
\hline Regorafenib & II & $\begin{array}{l}\text { BRAF }^{\mathrm{V} 600 \mathrm{E}}, \mathrm{BRAF}^{\mathrm{WT}}, \mathrm{CRAF}, \\
\text { RET, c-KIT, TIE2,VEGFR1, } \\
\text { VEGFR2, VEGFR3, FGFR1, } \\
\text { PDGFR } \beta \text {, }\end{array}$ & III & $\begin{array}{c}\text { Metastatic } \\
\text { Colorectal } \\
\text { Cancer }\end{array}$ & 760 & 160 & 1 & 0 & & 1.9 & 6.4 & $\mathrm{FDA}^{\mathrm{d}}$ & [104] \\
\hline XL281 & II & $\mathrm{BRAF}^{\mathrm{V} 600 \mathrm{E}}, \mathrm{BRAF}^{\mathrm{WT}}, \mathrm{CRAF}$ & I/II & $\begin{array}{c}\text { Metastatic } \\
\text { Colorectal } \\
\text { Cancer }\end{array}$ & & 150 & & & & & & & $\begin{array}{c}{[111]} \\
(\mathrm{NCT} 01086267)^{\mathrm{e}}\end{array}$ \\
\hline RAF265 & II & $\begin{array}{l}\text { BRAF }^{\mathrm{V} 600 \mathrm{E}}, \mathrm{BRAF}^{\mathrm{WT}} \text {, CRAF, } \\
\text { c-KIT, VEGFR2, PDGFR- } \beta\end{array}$ & II & $\begin{array}{l}\text { Metastatic } \\
\text { Melanoma }\end{array}$ & & 48 & & & & & & & $\begin{array}{c}{[112]} \\
(\mathrm{NCT} 00304525)^{\mathrm{e}} \\
\end{array}$ \\
\hline ARQ736 & Unknown & $\mathrm{BRAF}^{\mathrm{V} 600 \mathrm{E}}, \mathrm{BRAF}^{\mathrm{WT}}, \mathrm{CRAF}$ & I & $\begin{array}{c}\text { Advanced } \\
\text { Solid Tumor }\end{array}$ & & & & & & & & & $\begin{array}{c}{[114]} \\
(\mathrm{NCT} 01225536)^{\mathrm{e}} \\
\end{array}$ \\
\hline
\end{tabular}

WT: Wild Type; FDA: Food and Drug Administration, USA; b.i.d.: Twice Daily.

a. Approved by FDA for the treatment of patients with metastatic melanoma bearing BRAF ${ }^{\mathrm{V} 600 \mathrm{E}}$ mutation.

b. Median time to radiologic progression.

c. Approved by FDA for the treatment of patients with unresectable hepatocellular carcinoma and advanced renal cell carcinoma.

d. Approved by FDA for the treatment of patients with metastatic colorectal cancer and unresectable metastatic GI stromal tumors.

e. ClinicalTrials.gov registration identification number. 
